\title{
Comparing SLIM, SPAR-H and Bayesian Network Methodologies
}

\author{
Eduardo Calixto ${ }^{1}$, Gilson Brito Alves Lima ${ }^{2}$, Paulo Renato Alves Firmino ${ }^{3}$ \\ ${ }^{1}$ Energy Planning Engineer (Coppe), Rio de Janeiro, Brasil \\ ${ }^{2}$ Production Engineer Department, Fluminense Federal University (Uff), Rio de Janeiro, Brasil \\ ${ }^{3}$ Rural University of Pernambuco, Recife, Brasil \\ Email: eduardo.calixto@hotmail.com
}

Received March 7, 2013; revised April 5, 2013; accepted April 19, 2013

Copyright (C) 2013 Eduardo Calixto et al. This is an open access article distributed under the Creative Commons Attribution License, which permits unrestricted use, distribution, and reproduction in any medium, provided the original work is properly cited.

\begin{abstract}
Human factors always affect maintenance performance, and in some cases, it's critical to systems availability and reliability. Despite such importance, in so many cases, there's no human reliability method applied to analyze maintenance tasks in order to understand better human factors influence in maintenance performance. There are several human analysis methodologies and regarding human factors, SLIM (Successes Likelihood Methods), SPAR-H (Standardized Plant Analysis Risk-Human Reliability Analysis Method) and Bayesian Net take into account such factors and may be a good approach to minimize human error. In order to propose a human reliability methodology to analyze maintenance tasks taking into account human factors, a case study about turbine star up tasks will be carried out. Therefore, different human reliability methods will be performed based on specialist opinion. Finally, the human error probability as well as drawbacks and advantages from different methods will be discussed to get a final conclusion.
\end{abstract}

Keywords: Human Reliability Analysis; Human Performance Factor; Human Error Probability

\section{Introduction}

In 1958, Williams suggested to consider Human Reliability in system reliability analysis. Further in 1960, some reliability studies have shown that part of equipment failures had influence for human actions and in 1972, IEEE published a report about human reliability.

In 1975, Swain and Guttmann in order to solve some human failure in Atomic Reactors operation proposed the first Human Reliability approach. The THERP (Technique for Human Error Prediction) is a method to predict human error probabilities and to evaluate the degradation of a man-machine system likely to be caused by human errors alone or in connection with equipment functioning, operational procedures and practices, or other system and human characteristics that influence system behavior [1].

From seventies and decades on, several methodologies were proposed and published by U.S Nuclear Regulatory Commission (USNRC) and other industries and Governmental Organizations.

Definitely, the Human reliability methods developments were three stages time. The first on last twenty years (1970-1990) is known as First Human Reliability Methods Generation, which focuses on human error probabilities and operational human error.

The Second phase, the next ten years approximately (1990-2005) is known as second Human Reliability Methods Generation focus in Human performance Factor and cognitive processes. Human performance factors are internal or external and in general are everything that take influence in human performance like workload, stress, sociological issues, psychological issues, illness, etc.

Finally, third phase stated in 2005 until today and is represented for methods which focus on human performance factors relations and dependencies. That is Third Human Reliability Methods Generation.

No matter aspects regarded in Human Reliability Methods, nowadays they are applied by different industries in order to reduce accidents, and cost of human error in operation and maintenance activities.

The MHIDAS data reports that from 247 accidents in refinery, $21.86 \%$ is related to human failure [2].

In pipeline enterprises, $41 \%$ of system failures have human error as root cause. Operation is responsible for $22 \%$ and maintenance is responsible for $59 \%$ [3].

In order to apply such methodologies, it required human failures data that is collected in historical data's procurements or specialist opinion. 
Actually, there are several ways of aggregating several experts' opinions: they can estimate alone, with their opinions then aggregated mathematically; or they can estimate alone but have limited discussions for clarification purposes; or they can meet as a group and discuss their estimates until they reach a consensus [4]. Thus the cases options are:

- Aggregated Individual Method; this method entails that the experts do not meet but make estimates individually. These estimates are then aggregated statistically by taking the geometric mean of all the individual estimates for each task.

- Delphi Method; experts make their assessments individually and then all the assessments are shown to all the experts.

- Nominal Group Technique; this method is similar to the Delphi Method, but after the group discussion, each expert makes his or her own assessment. These assessments are then statistically aggregated.

- Consensus Group Method; in this method, each member contributes to the discussion, but the group as a whole must then arrive at an estimate upon which all members of the group agree.

In Brazil OIL and gas industry, there's low quantity of data about human error and mostly specialist opinion is required. Many of Human Reliability analysis in last ten years were applied in drilling projects and Bayesian Network, third Generation Human Reliability Method, is the main Human Reliability Methods. In order to obtain human failures data, aggregated individual methods were applied in most of cases. Thus, specialist opinion elicitation based in Bayes Methods.

In order to increase Human reliability analysis in Brazilian Oil \& Gas downstream applications (project, maintenance, building and operational), Human Reliability Methods case study of compressor startup were carried out. The Consensus-Group Method to collect specialist opinion about human failures probability and in addition, Second and Third Human Reliability Methods Generation were applied.

\section{Human Reliability Concepts}

First, confirm that you have the correct template for your Human reliability is probability of human carried out specific tasks with satisfactory performance. That concept can be applied to different tasks like equipment repair, equipment or system operation, safety action, analysis and all kind of human action which takes influence in system performance. Thus, came out the main questions that Human Reliability Analysis will try to answer:

- What can be wrong?

- Which are the Human failure consequences?

- Which Human performance factors take influence in human reliability?
- What is necessary to improve human reliability to avoid or prevent human error?

In order to answer such question an appropriate methods must be applied and it's depends on:

- Human Analysis objectives, it means, is applied to investigate incident, to improve maintenance procedures, to improve operational steps.

- The second critical point is which human failures data are available to performance analysis. To perform HRA is necessary specialist opinion or to use human failure data available.

- The last and one of most critical issue is time to perform analysis, because depends on methodology, is required specialist and software as main resources. Time is always critical issue because human reliability analysis can last for hours or days.

In order to decide which HRA methods to apply, regarding three critical issues above, is necessary to know about such methods their objectives and limitation. Depends on HRA method, the focus is on human error probability prediction, understand human error in cognitive process or understand human performance factors influence on human error. By definition, human error can be:

- Omission Error happens when one action is not performed due to lapse or misperception. As instance, in preventive incident action, omission error is misperception of alarm and not performs action required. Equipment degradation due repair is omission error when due lapse, steps of procedures are not performed.

- Commission Error happens when action is performed wrongly due to wrong quantity or quality of action or mistake in select or procedure sequence. As instance, in preventive incident action, commission error is select wrong command or make mistake in sequence of actions required. Equipment degradation due repair is commission error when repair is performed wrongly.

- Intentional Error happens when action is performed or procedure steps are not followed with awareness about consequences. As instance, in preventive incident action, that happen when operator do not follow safety procedure completely to reestablish system faster. Equipment degradation would occur when intentional wrong action is performed during repairs like put some tools into equipment intentionally before close equipment to cause some damage.

Actually, so many factors influence in human error like Human performance factors and human behavior. Internal human performances factors depend on each individual characteristic and they are:

- Psychological: Stress, over psychological workload, depression, demotivation, not concentrated.

- Physiologic: health conditions, deceases. 
Such factors may be monitored in order to guarantee that employees will be in better physical and psychological shape to performed critical actions.

- External human performances factor depends on company and society and they are:

- Technological: procedures, equipment, work conditions.

- Social: bad social conditions, bad acceptance in group.

By this way, there must be some social issues that company has not control and ways to interfere and its take some influence in employees behavior. By the other way round, technological issues depends on companies and as better as such conditions is expected better employees performance. Figure 1 show HRA factors which take influence in Human error.

Behavior in action, it means maintenance, operation or preventive incident sequence action, are performed based in procedure, skill and knowledge.

When Action based in procedure is carried out, procedure has high influence in action performance mainly when employees have not high experience in execute task.

When action based in skill is carried out, human performance has high influence by practical experience in specific task and time to perform that [5].

When action based knowledge is carried out human performance have high influence by time and task complexity which require time enough to information be processed and implemented.
In order to perform HRA is also necessary to know HRA methods feature. The Table 1 focus on first HRA methods generation which main objective is defines sequence of action and human error probability.

The Table 2 gives examples of second and third HRA Methods Generation which main objective is human cognitive process and human's factor dependency respectively.

Actually, depends on HRA objective and problem characteristic, is advisable to implement the most appropriated method in order to be succeed. Whenever is it possible to apply more than one method and compare results is great because it gives you a chance to certify results about which human performance factor take more influence in human error.

The next topics will explain different HRA methods that will be applied further to analyses human error during a turbine start up task.

\section{SPAH-R Method}

In support of the Accident Sequence Precursor Program (ASP), the U.S. Nuclear Regulatory Commission (NRC), in conjunction with the Idaho National Laboratory (INL), in 1994 developed the Accident Sequence Precursor Standardized Plant Analysis Risk Model (ASP/SPAR) human reliability analysis (HRA) method, which was used in the development of nuclear power plant (NPP) models. Based on experience gained in field testing, this method was updated in 1999 and renamed SPAR-H,

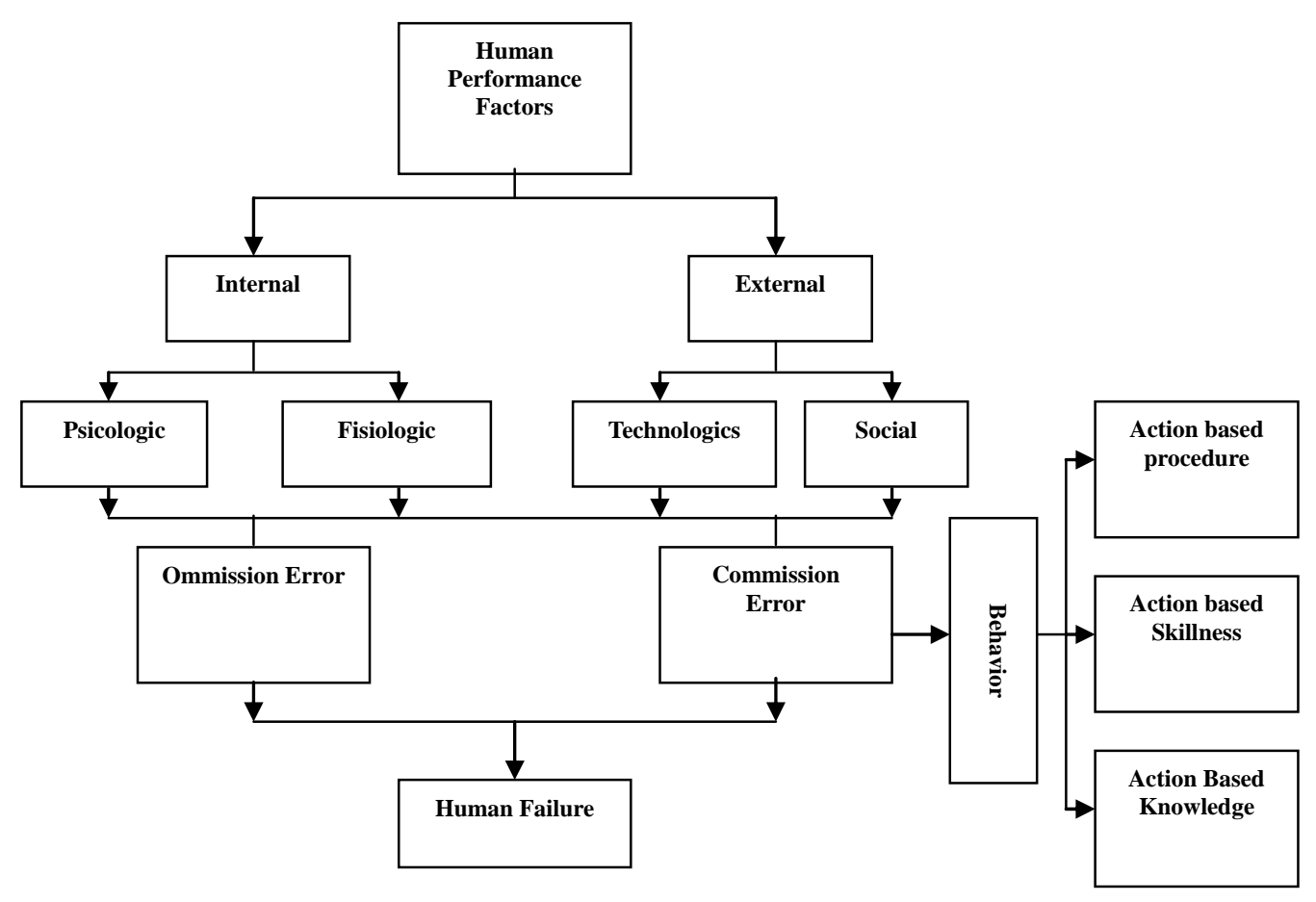

Figure 1. Influence factors in human error. Source: Calixto, 2011. 
Table 1. First generation. Source: Calixto, 2011.

\begin{tabular}{|c|c|c|}
\hline \multicolumn{3}{|c|}{ Human Reliability Analysis Methods } \\
\hline \multicolumn{3}{|r|}{ First Generation } \\
\hline THERP & $\begin{array}{l}\text { Technique for human error rate } \\
\text { prediction }\end{array}$ & $\begin{array}{l}\text { Assess failure in task or action sequence. It is applied in maintenance, operational or } \\
\text { incident analysis with complex graphic representation. (1975) }\end{array}$ \\
\hline OAT & Operator action trees & $\begin{array}{l}\text { Assess failure in task or action sequence. It is applied in maintenance, operational or } \\
\text { incident analysis with simple graphic representation. (1982) }\end{array}$ \\
\hline SLIM & Success likelihood Index Methodology & $\begin{array}{l}\text { Assess failure in task or action sequence and is applied in maintenance, operational } \\
\text { or incident analysis and regards human factors performance based in specialist } \\
\text { opinion. (1984) }\end{array}$ \\
\hline SHARP & $\begin{array}{l}\text { Systematic Human Action Reliability } \\
\text { Procedure }\end{array}$ & $\begin{array}{l}\text { Assess cognitive human process of failure (detection, understanding, decision and } \\
\text { action), being applied in maintenance, operational or incident analysis. (1984) }\end{array}$ \\
\hline
\end{tabular}

Table 2. Second generation. Source: Calixto, 2011.

\begin{tabular}{|c|c|c|}
\hline \multicolumn{3}{|c|}{ Human Reliability Analysis Methods } \\
\hline \multicolumn{3}{|r|}{ Second Generation } \\
\hline ATHEANA & $\begin{array}{l}\text { A Technique for Human } \\
\text { Error Analysis }\end{array}$ & $\begin{array}{l}\text { Assess cognitive human process of failure (detection, understanding, decision and } \\
\text { action), being applied in maintenance, operational or incident analysis. (1996) }\end{array}$ \\
\hline CREAM & & Third Generation \\
\hline Name & \multicolumn{2}{|r|}{ Objective } \\
\hline Redes Bayesianas & \multicolumn{2}{|c|}{$\begin{array}{l}\text { Assess failure in task or action sequence and is applied in maintenance, operational or incident analysis and } \\
\text { regards human factors performance based in specialist opinion. In addition such methods regards human factors } \\
\text { performance dependency.(2005) }\end{array}$} \\
\hline
\end{tabular}

Standardized Plant Analysis Risk-Human Reliability Analysis method [6].

The main objective is to define human failure probability regarding human performance factor influence. Such methodology requires specialist opinion in order to define human factors influence that follows standard file with values. The PSF (performance factors, will comprise HEP (Human Error Probability) in Equation (1) as shown below.

The SPAR-H method is straightforward, easy to apply, and is based on a human information processing model of human performance and results from human performance studies available in the behavioral sciences literature [6].

\section{SLIM Method}

In 80 ages, The U.S. Nuclear Regulatory Commission has embarked upon a multiyear research program to investigate different methods for using expert judgments to estimate human error probabilities in nuclear power plants. One of the methods investigated, derived from multi-attribute utility theory, is the Success Likelihood Index Methodology implemented through Multi-Attribute Utility Decomposition (SLIM-MAUD).

Brookhaven National Laboratory (BNL) developed and evaluated one method of obtaining human reliability estimates from expert judges - the Success Likelihood Index Methodology (SLIM). SLIM comprises a set of procedures based on Multi-Attribute Utility Theory for eliciting and organizing estimates by experts of the probability of success or failure of specific human actions in nuclear power plants.

The feasibility and implementability of SLIM were evaluated in a multiphase investigation. In the first phase, the basic characteristics of SLIM were defined [7]. Phases 2 and 3 consisted of an experimental evaluation and field test of SLIM. In Phase 4, SLIM was linked to an interactive computer program based upon Multi-Attribute Utility Decomposition (MAUD), and proc- 
Table 3. PSF values. Source: NUREG, CR-6883.

\begin{tabular}{|c|c|c|}
\hline PSFs & PSF Level & $\begin{array}{l}\text { Multiplier for } \\
\text { Ation }\end{array}$ \\
\hline \multirow{6}{*}{$\begin{array}{l}\text { Available } \\
\text { time }\end{array}$} & Inadequate Time & $P(f)=1$ \\
\hline & $\begin{array}{c}\text { Time Available Time } \\
\text { required }\end{array}$ & 10 \\
\hline & Nominal time & 1 \\
\hline & $\begin{array}{c}\text { Time Available }{ }^{3} 5 \times \text { Time } \\
\text { required }\end{array}$ & 0.1 \\
\hline & $\begin{array}{l}\text { Time Available }{ }^{3} 50 \times \text { Time } \\
\text { required }\end{array}$ & 0.01 \\
\hline & Insufficient information & 1 \\
\hline \multirow{4}{*}{ Stress } & Estreme & 5 \\
\hline & High & 2 \\
\hline & Nominal & 1 \\
\hline & Insufficient information & 1 \\
\hline \multirow{4}{*}{ Complexity } & Highly complex & 5 \\
\hline & Moderatey complex & 2 \\
\hline & Nominal & 1 \\
\hline & Insufficient information & 1 \\
\hline \multirow{4}{*}{$\begin{array}{l}\text { Experience/ } \\
\text { Training }\end{array}$} & Low & 3 \\
\hline & Nominal & 1 \\
\hline & High & 0.5 \\
\hline & Insufficient information & 1 \\
\hline \multirow{5}{*}{ Procedures } & Not Available & 50 \\
\hline & Incomplete & 20 \\
\hline & Available, but poor & 5 \\
\hline & Nominal & 1 \\
\hline & Insufficient information & 1 \\
\hline \multirow{5}{*}{ Ergonomics } & Missing/Misleading & 50 \\
\hline & Poor & 10 \\
\hline & Nominal & 1 \\
\hline & Good & 0.5 \\
\hline & Insufficient information & 1 \\
\hline \multirow{4}{*}{$\begin{array}{l}\text { Fitness for } \\
\text { dutty }\end{array}$} & Unfit & $P(f)=1$ \\
\hline & Degrate fitness & 5 \\
\hline & Nominal & 1 \\
\hline & Insufficient information & 1 \\
\hline \multirow{4}{*}{$\begin{array}{l}\text { Work } \\
\text { proess }\end{array}$} & Poor & 5 \\
\hline & Nominal & 1 \\
\hline & Good & 0.5 \\
\hline & Insufficient information & 1 \\
\hline
\end{tabular}

dures for applying the resultant SLIM-MAUD methodology were developed [7].
Following a description of the method [7], the SLIM methods steps are:

1) Constitution of the group of experts and first approach to the case of analysis.

2) Definition and selection of the Performance shaping factors for the case of analysis.

3) Assignment of weighting factors for each PSF.

4) Scoring of each PSF.

5) Calculation of the success likelihood index.

6) Conversion of the SLI in HEP.

The first step requires knowing what is being assessed and which employee have a good idea about problem in order to identify PSF and which one take more influence in such human error in activity.

Further, once the right group to carry out analysis, is defined which human performance factors take into account it weight which vary from $0 \%$ to $100 \%$. As doing so, it necessary to score each PSF per each task and mostly scores vary from 1 to 9, depends on PSF characteristics. In cases of PSF's high performance required, for example training level, the best score is 9. By the other way round, in cases of lower PSF's performance required, for example stress, the best score is 1 (Table 3).

Is advisable to make up one table which describes tasks and PSFs to be easier to understand and calculate HEP. Table 4 below describes PSFs regarded to be assessed in SLIM method with specialist opinion about PSFs level.

After define score for PSF and its weights is necessary to calculate SLIM multiplying scores per weights and adds values to have one slim per task as shown in Table 5.

Table 5 was considered as weights for each PSF:

Table 4. Slim table.

\begin{tabular}{cccc}
\hline \multicolumn{4}{c}{ Score Table } \\
\hline Task & Procedure & Training & Supervision \\
\hline Task 1 & 6 & 8 & 9 \\
Task 2 & 7 & 8 & 9 \\
Task 3 & 6 & 9 & 9 \\
Task 4 & 9 & 8 & 9 \\
\hline
\end{tabular}

Table 5. Slim table with scores and weighs.

\begin{tabular}{ccccc}
\hline \multicolumn{5}{c}{ Score Table } \\
\hline Task & Procedure & Training & Supervision & SLIM \\
\hline Task 1 & $6 \times 0.5$ & $8 \times 0.3$ & $9 \times 0.2$ & 7.2 \\
Task 2 & $7 \times 0.5$ & $8 \times 0.3$ & $9 \times 0.2$ & 7.7 \\
Task 3 & $6 \times 0.5$ & $9 \times 0.3$ & $9 \times 0.2$ & 7.5 \\
Task 4 & $9 \times 0.5$ & $8 \times 0.3$ & $9 \times 0.2$ & 8.5 \\
\hline
\end{tabular}


$\Rightarrow 20 \%$ for Supervision;

$\Rightarrow 50 \%$ for procedure;

$\Rightarrow 20 \%$ Training.

After calculate slim is necessary to calculate HEP using Equation (2) below.

$$
\log \mathrm{P}=\mathrm{aSLI}+\mathrm{b}
$$

In order to define "a" and " $b$ " values, is necessary to know two values of HEP that in equation is P and SLI to solve equation. Thus, with HEP calculated for each task is necessary to calculate final HEP that will be the sums of all HEPs.

\section{Bayesian Network Method}

The Network Bayesian methodology was developed in 80 ages to make easier prediction in Artificial Intelligence analysis [8]. It can be defined as graphic frameworks which represents arguments in uncertain domain [9]. Such framework are unicycle Graphs cause it cannot make up closed cycles and have only one direction. The node represents random variables and arcs represent direct dependency between variables relations. The arcs direction represents cause effect relation between variables [8]. In figure below the network Bayesian is represented being node $\mathrm{C}$, consequence from cause $\mathrm{A}$ and $\mathrm{B}$.

In Figure 2, node $A$ and $B$ are sons of $C$ and node $C$ is called ancestral of $\mathrm{A}$ and $\mathrm{B}$, in other words, $\mathrm{C}$ is called father of $A$ and B. In Human Reliability analysis, the Nodes A and B represents Performance human factor and node $\mathrm{C}$ represents Human error probability conditioned to human performance factors A and B. As usual, The Human Performance factor represented by nodes A and B can be internal (Stress, over workload, depression, demotivation, health conditions, deceases) or external (procedures, equipment, work conditions, bad social conditions, bad acceptance in group).

Into each node there's conditional PDF (probability density function) which represent variables values along time when random variable represent such event when

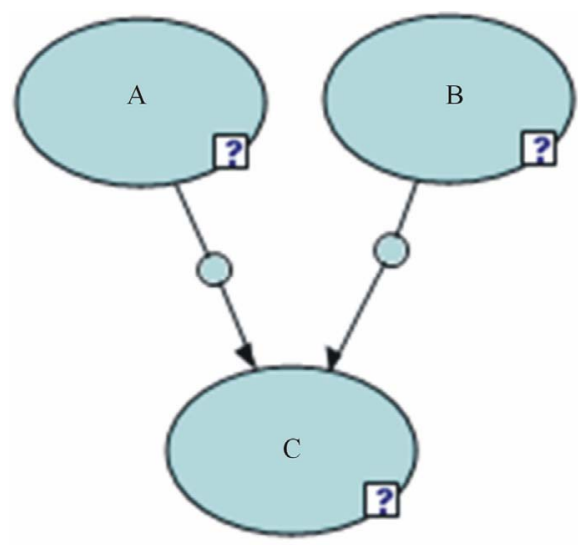

Figure 2. Bayesian network. Author: Calixto, 2011. it's not there's a constant conditional probability value. The Equation (3) below shows Bayes equation.

$$
\mathrm{P}(\mathrm{A} \mid \mathrm{B})=\frac{\mathrm{P}(\mathrm{B} \mid \mathrm{A}) \times \mathrm{P}(\mathrm{A})}{\mathrm{P}(\mathrm{B})}
$$

The methodology Bayesian belief networks (BBN) provides a greater flexibility as not it only allows for a more realistic representation of the dynamic nature of man-system, but also allows for representation of the relationship of dependence among the events and performance shaping factors [10].

\section{Maintenance Case Study}

The maintenance case study analyzes human failure in sequence procedure to star up a turbine after maintenance. The startup is considered maintenance group task and require for steps:

$\Rightarrow$ STEP 1 -Close Vapor Valve;

$\Rightarrow$ STEP 2-Close Suction Valve;

$\Rightarrow$ STEP 3-Open Suction Valve;

$\Rightarrow$ STEP 4-Open Vapor Valve.

In case of failure in startup sequence tasks the Turbine shut down and may have damage that last from $2 \mathrm{~h}$ to 1 month to be fixed. The turbine shutdown does not cause any damage to other System but the monetary consequence to use private electric energy varies from U\$ 1.25000 to U\$ 450.00000 respectively.

The stat up procedure was carried out for one inexperience employee and his supervisor checked out his steps realizing that sequence was proceeded wrongly having time to be corrected for supervisor. Further, the failure was assessed and was implemented improvement in procedure that was not clear enough.

In order to find out how much loss of money is expected in case of start up turbine failure was carried out HRA to define human failure probability before and after improvement.

Consensus-Group Method were applied to define scores values, by this way, each member contributed to the discussion and define values scores.

The main objective of case study is defining human error probability and furthermore, compares different HRA methods in order to implement in operational routine to assessment of human failure. As doing so three methods (SPAH, SLIM and Bayesian Network) will be carried out and compared.

\subsection{SPAR-H}

The template is designed so that author affiliations are Identify the Headings

The SPAR-H method was carried out in order to define human failure probability and two experience op- 
erators estimate human probability values to human failures in tasks 1 to 4 . As doing so, the operator opinion was considered to describe PSFs composite too. In general SPAR-H method is used to assess a complete activity but in this case the Equation (3) below was applied to define Human Error Probability.

$$
\mathrm{HEP}=\frac{\mathrm{NHEP} \cdot \mathrm{PSF}_{\text {composite }}}{\mathrm{NHEP} \cdot\left(\mathrm{PSF}_{\text {composite }}-1\right)+1}
$$

The Table 6 below shows PSFs composite values for each task.

By this way, is possible to observe that PSFs had same values, because tasks is very similar and is considered that are affected the same way by PSFs.

As doing so, the availability time was considered adequate, nominal stress level, nominal complexity, poor procedure, nominal ergonomics, nominal fitness for duty and nominal work process. Nominal qualification means that such PSFs are under good conditions and have low influence in failure. The Table 7 shows Human Error probabilities. HEP1 regards specialist opinion about task human error probability. The SPAR-H procedures suggest to use 0.1 to HEP in commission error and 0.001 to omission error. In this case, was considered specialist opinion and for each task was defined HEP that is stated in HEP1 column. Further, the column HEP2 de fine HEP regarding PSFs influence applying Equation (3) and final Human error probability is $56 \%$.

Table 6. PSFs composite (before improvement).

\begin{tabular}{ccccc}
\hline PSFs & Task 1 & Task 2 & Task 3 & Task 4 \\
\hline Available time & 1 & 1 & 1 & 1 \\
Stress & 1 & 1 & 1 & 1 \\
Complexity & 1 & 1 & 1 & 1 \\
Experience/Training & $\mathbf{1}$ & $\mathbf{1}$ & $\mathbf{1}$ & $\mathbf{1}$ \\
Procedures & $\mathbf{5}$ & $\mathbf{5}$ & $\mathbf{5}$ & $\mathbf{5}$ \\
Ergonomics & 1 & 1 & 1 & 1 \\
Fitness for dutty & 1 & 1 & 1 & 1 \\
Work proess & $\mathbf{1}$ & $\mathbf{1}$ & $\mathbf{1}$ & $\mathbf{1}$ \\
Total & 5 & 5 & 5 & 5 \\
\hline
\end{tabular}

Table 7. PSFs composite (before improvement).

\begin{tabular}{ccc}
\hline & HEP2 & HEP1 \\
\hline Open Vapor Valve-Task 1 & 0.357143 & 0.1 \\
Open Suction Valve-Task 2 & 0.0005 & 0.0001 \\
Close Suction Valve-Task 3 & 0.208333 & 0.05 \\
Open Vapor Valve-Task 4 & 0.0005 & 0.0001 \\
Total & 0.566476 & \\
\hline
\end{tabular}

In order to reduce Human Error Probability, were proposed improvement in procedure to makes it clearest. As doing so, the new values to PSFs are shown in Table 8 below.

By the human reliability point of view, regarding specialist opinion, all PSFs are nominal after procedure improvements having high influence in final Human Error Probability as show in Table 9. Thus, the final Human Error probability is now $15.02 \%$.

Regarding $56 \%$ of Human Error Probability the expected cost of human failure vary from U\$ 700.00 to U\$ 252.00000 in optimist and pessimist terms respectively.

After improvement, regarding 15\% of Human Error Probability the expected cost of human failure vary from U\$ 187.00 to U\$ 67.50000. The reduction in cost vary from U\$ 513.00 to U\$ 184.50000 .

The group of specialist which carried out the SPAR-H analysis regarded about method that:

$\Rightarrow$ SPAR-H is easy to be implemented;

$\Rightarrow$ The omission and commission Human Error Probability must represent turbine case study and specialist opinion must be regarded to define it;

$\Rightarrow$ It's possible in some cases to be other human performance factor that is not considered in SPAR-H procedure and in this case some of human performance factor in procedure would be take place.

Table 8. PSFs composite (after improvement).

\begin{tabular}{ccccc}
\hline PSFs & Task 1 & Task 2 & Task 3 & Task 4 \\
\hline Available time & 1 & 1 & 1 & 1 \\
Stress & 1 & 1 & 1 & 1 \\
Complexity & 1 & 1 & 1 & 1 \\
Experience/Training & $\mathbf{1}$ & $\mathbf{1}$ & $\mathbf{1}$ & $\mathbf{1}$ \\
Procedures & $\mathbf{1}$ & $\mathbf{1}$ & $\mathbf{1}$ & $\mathbf{1}$ \\
Ergonomics & 1 & 1 & 1 & 1 \\
Fitness for dutty & 1 & 1 & 1 & 1 \\
Work proess & $\mathbf{1}$ & $\mathbf{1}$ & $\mathbf{1}$ & $\mathbf{1}$ \\
Total & 1 & 1 & 1 & 1 \\
\hline
\end{tabular}

Table 9. PSFs composite (after improvement).

\begin{tabular}{ccc}
\hline & HEP2 & HEP1 \\
\hline Open Vapor Valve_Task 1 & 0.1 & 0.1 \\
Open Suction Valve_Task 2 & 0.0001 & 0.0001 \\
Close Suction Valve_Task 3 & 0.05 & 0.05 \\
Open Vapor Valve_Task 4 & 0.0001 & 0.0001 \\
Total & 0.1502 & \\
\hline
\end{tabular}




\subsection{SLIM Case Study Application}

The second method is SLIM and such procedure in applied to Turbine Case. Thus, the first step was to define PSFs regarding specialist opinion and in this case is procedure, training and supervision was defined. The next step is to give score importance in terms of lever of compliance to each PSF for each task. In this case scores vary from 1 to 9 , and 9 means the highest compliance. Table 10 shows PSF scores based in specialist opinion. In this case the score are the same for all tasks because it similarity.

The next step is necessary to define importance for each PSFs varying from $0 \%$ to $100 \%$. Total importance sums of all scores must be $100 \%$. Thus the Table 11 shows importance to each PSF.

The next step is defined SLI, multiplying Scores per each PSFs values as shown in Table 12.

The next step is necessary to define HEP for each task and after to total start up activity. Thus, is necessary to define variables values for Equation (4).

$$
\log \mathrm{P}=\mathrm{aSLI}+\mathrm{b}
$$

In order to define "a" and "b" parameters, is necessary to have P (HEP) value that can be considered by specialist

Table 10. Scores values (before improvement).

\begin{tabular}{cccc}
\hline \multicolumn{4}{c}{ Score Table } \\
PF rate & Procedure & Trainning & Supervision \\
\hline Open Vapor Valve_-Task 1 & 6 & 8 & 9 \\
Open Suction Valve_-Task 2 & 6 & 8 & 9 \\
Close Suction Valve_-Task 3 & 6 & 8 & 9 \\
Open Vapor Valve_-Task 4 & 6 & 8 & 9 \\
\hline
\end{tabular}

Table 11. Importance values (before improvement).

\begin{tabular}{cc}
\hline \multicolumn{3}{c}{ PSFs Importance } \\
\hline Procedure & $50 \%$ \\
Trainning & $30 \%$ \\
Supervision & $20 \%$ \\
Total & $100 \%$ \\
\hline
\end{tabular}

Table 12. SLI values (before improvement).

\begin{tabular}{ccccc}
\hline \multicolumn{5}{c}{ SLI Table } \\
Tasks & Procedure & Trainning & Supervision & SLI \\
\hline Open Vapor Valve_-Task 1 & 3 & 2.4 & 1.8 & 7.2 \\
Open Suction Valve_-Task 2 & 3 & 2.4 & 1.8 & 7.2 \\
Close Suction Valve_-Task 3 & 3 & 2.4 & 1.8 & 7.2 \\
Open Vapor Valve_-Task 4 & 3 & 2.4 & 1.8 & 7.2 \\
\hline
\end{tabular}

opinion. As doing so, regarding 0.1 and 0.0001 for task one and two respectively. The final equation will enable to calculate HEP for each task, thus Equation (5) will be:

$$
\mathrm{HEP}=10^{(-0.24 \times \mathrm{SLI}+0.18)}
$$

The final step is applying SLI value for each task in Equation (5). The Table 13 below shows the final Human Error probability.

By analyst point of view, procedure is the PSFs which take more influence in human error probability. As doing so, after procedure improvement is expected that final probability reduce to $10 \%$. The new expected score to procedure value is 9 as show in Tables $\mathbf{1 4}$ and $\mathbf{1 5}$.

The next steps are modifying importance values and in this case procedure importance will reduce due to not take more high influence in Turbine start up.

The new SLI value is show in Table $\mathbf{1 6}$ below regarding new scores and importance values.

The final step is defining new HEP for each task and after to total start up activity regarding procedure improvement. Thus, is necessary to define again variables values for equation below.

$$
\log \mathrm{P}=\mathrm{aSLI}+\mathrm{b}
$$

\begin{tabular}{|c|c|c|}
\hline \multirow{2}{*}{ Tasks } & $\mathrm{aSLI}+\mathrm{b}$ & \multirow{2}{*}{$10^{(-0.24 \times \mathrm{SL}+0.18)}$} \\
\hline & $(-0.024 * \mathrm{SLI})+0.18$ & \\
\hline Open Vapor Valve-Task 1 & -1 & 0.10 \\
\hline Open Suction Valve-Task 2 & -1 & 0.10 \\
\hline Close Suction Valve-Task 3 & -1 & 0.10 \\
\hline \multirow[t]{2}{*}{ Open Vapor Valve-Task 4} & -1 & 0.10 \\
\hline & Total & $40 \%$ \\
\hline
\end{tabular}

Table 13. SLI values (before improvement).

Table 14. Scores values (after improvement).

\begin{tabular}{cccc}
\hline \multicolumn{4}{c}{ Score Table } \\
\hline PF rate & Procedure & Trainning & Supervision \\
\hline Open Vapor Valve-Task 1 & 9 & 8 & 9 \\
Open Suction Valve-Task 2 & 9 & 8 & 9 \\
Close Suction Valve-Task 3 & 9 & 8 & 9 \\
Open Vapor Valve-Task 4 & 9 & 8 & 9 \\
\hline
\end{tabular}

Table 15. Importance values (after improvement).

\begin{tabular}{cc}
\hline \multicolumn{1}{c}{ PSFs Importance } \\
\hline Procedure & 0.1 \\
Trainning & 0.5 \\
Supervision & 0.4 \\
Total & 1 \\
\hline
\end{tabular}


Table 16. SLI values (after improvement).

\begin{tabular}{cccccc}
\hline \multicolumn{5}{c}{ SLI Table } \\
\hline Tasks & Procedure & Trainning & Supervision SLI \\
\hline Open Vapor Valve_-Task 1 & 0.9 & 4 & 3.6 & 8.5 \\
Open Suction Valve-Task 2 & 0.9 & 4 & 3.6 & 8.5 \\
Close Suction Valve-Task 3 & 0.9 & 4 & 3.6 & 8.5 \\
Open Vapor Valve-Task 4 & 0.9 & 4 & 3.6 & 8.5 \\
\hline
\end{tabular}

In order to define new " $a$ " and " $b$ " parameters, is necessary to have P (HEP) value that can be considered by specialist opinion after procedure improvement. As doing so, regarding 0.01 and 0.0001 for task one and two respectively. The final equation will enable to calculate HEP for each task, thus Equation (7) will be:

$$
\mathrm{HEP}=10^{(3 \times \mathrm{SLI}-27.18)}
$$

The final step is again applying new SLI values for each task in Equation (7). The Table 17 below shows the final Human Error probability.

Regarding $40 \%$ of Human Error Probability the expected cost of human failure vary from U\$ 500.00 to U\$ 180.00000 in optimist and pessimist terms respectively.

After improvement, regarding 10\% of Human Error Probability the expected cost of human failure vary from U\$ 125.00 to U\$ 45.00000. The reduction in cost varies from U\$ 375.00 to U\$ 135.00000 .

The group of specialist which carried out the SLIM analysis regarded about method that:

$\Rightarrow$ SLIM is not easy to be implemented because beyond specialist opinion requires mathematics treatments;

$\Rightarrow$ The specialist opinion takes high influence in HEP value;

\subsection{Bayesian Network Case Application}

The final method is from Third Human Reliability Generation and the advantage is to consider PSFs conditional probability related with human error probability.

Thus, regarding as main PSFs, procedure, supervision and training, the Bayesian Network is represented as Figure 3.

Thus, $\mathrm{HEP}=\mathrm{P}(\mathrm{C}=1)$. In general, $\mathrm{P}(\mathrm{ST}=1)$. Thus:

$$
\begin{aligned}
\mathrm{HEP}= & \sum_{i=0}^{1} \sum_{j=0}^{1} \sum_{k=0}^{1} \mathrm{P}\left(\mathrm{T}_{1}=i\right) \times \mathrm{P}\left(\mathrm{P}_{2}=j\right) \times \mathrm{P}\left(\mathrm{S}_{3}=k\right) \\
& \times \mathrm{P}\left(\mathrm{ST}=1 \mid \mathrm{T}_{1}=i, \mathrm{P}_{2}=j, \mathrm{~S}_{3}=k\right)
\end{aligned}
$$

where:

$\mathrm{ST}=$ human error in start up turbine $=(\mathrm{ST}=1)$

$\mathrm{T}=$ good training $\left(\mathrm{T}_{i}=0\right)$

$\mathrm{T}=$ bad training $\left(\mathrm{T}_{i}=1\right)$

$\mathrm{P}=$ Good procedure $\left(\mathrm{P}_{i}=0\right)$

\begin{tabular}{|c|c|c|}
\hline \multirow{2}{*}{ Tasks } & $\mathrm{aSLI}+\mathrm{b}$ & \multirow{2}{*}{$\mathrm{HEP}=10^{(3 \times \mathrm{SLI}-27.18)}$} \\
\hline & $(3 * \mathrm{SLI})-27.1$ & \\
\hline Open Vapor Valve_-Task 1 & -2 & 0.03 \\
\hline Open Suction Valve-Task 2 & -2 & 0.03 \\
\hline Close Suction Valve-Task 3 & -2 & 0.03 \\
\hline \multirow[t]{2}{*}{ Open Vapor Valve_-Task 4} & -2 & 0.03 \\
\hline & Total & $10 \%$ \\
\hline
\end{tabular}

$\mathrm{P}=\operatorname{Bad}$ procedure $\left(\mathrm{P}_{i}=1\right)$
Table 17. SLI values (after improvement).

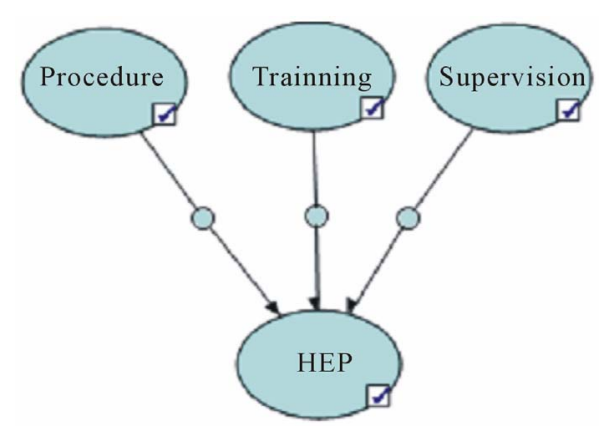

Figure 3. Start up turbine Bayesian network. Author: Calixto, 2011.

$$
\begin{aligned}
& \mathrm{S}=\operatorname{good} \text { Supervision }\left(\mathrm{S}_{i}=0\right) \\
& \mathrm{S}=\text { bad Supervision }\left(\mathrm{S}_{i}=1\right) \\
& \text { Thus, } \\
& \begin{aligned}
\mathrm{HEP}= & \mathrm{P}(\overline{\mathrm{ST}} \mid \overline{\mathrm{T}}, \overline{\mathrm{P}}, \overline{\mathrm{S}}) \times \mathrm{P}(\overline{\mathrm{T}}) \times \mathrm{P}(\overline{\mathrm{P}}) \times \mathrm{P}(\overline{\mathrm{S}}) \\
& +\mathrm{P}(\overline{\mathrm{ST}} \mid \mathrm{T}, \overline{\mathrm{P}}, \overline{\mathrm{S}}) \times \mathrm{P}(\mathrm{T}) \times \mathrm{P}(\overline{\mathrm{P}}) \times \mathrm{P}(\overline{\mathrm{S}}) \\
& +\mathrm{P}(\overline{\mathrm{ST}} \mid \overline{\mathrm{T}}, \overline{\mathrm{P}}, \mathrm{S}) \times \mathrm{P}(\overline{\mathrm{T}}) \times \mathrm{P}(\overline{\mathrm{P}}) \times \mathrm{P}(\mathrm{S}) \\
& +\mathrm{P}(\overline{\mathrm{ST}} \mid \mathrm{T}, \overline{\mathrm{P}}, \mathrm{S}) \times \mathrm{P}(\mathrm{T}) \times \mathrm{P}(\overline{\mathrm{P}}) \times \mathrm{P}(\mathrm{S}) \\
& +\mathrm{P}(\overline{\mathrm{ST}} \mid \overline{\mathrm{T}}, \mathrm{P}, \overline{\mathrm{S}}) \times \mathrm{P}(\overline{\mathrm{T}}) \times \mathrm{P}(\mathrm{P}) \times \mathrm{P}(\overline{\mathrm{S}}) \\
& +\mathrm{P}(\overline{\mathrm{ST}} \mid \mathrm{T}, P, \overline{\mathrm{S}}) \times \mathrm{P}(\mathrm{T}) \times \mathrm{P}(\mathrm{P}) \times \mathrm{P}(\overline{\mathrm{S}}) \\
& +\mathrm{P}(\overline{\mathrm{ST}} \mid \overline{\mathrm{T}}, \mathrm{P}, \mathrm{S}) \times \mathrm{P}(\overline{\mathrm{T}}) \times \mathrm{P}(\mathrm{P}) \times \mathrm{P}(\mathrm{S}) \\
& +\mathrm{P}(\overline{\mathrm{ST}} \mid \mathrm{T}, \mathrm{P}, \mathrm{S}) \times \mathrm{P}(\mathrm{T}) \times \mathrm{P}(\mathrm{P}) \times \mathrm{P}(\mathrm{S})
\end{aligned}
\end{aligned}
$$

In order to calculate HEP is necessary to get specialist opinion to define probability value as shows in questionnaire below.

Specialist Opinion Questionnaire:

1) What is the probability to failure in start up turbine if procedure is not good? (Optimist $=60 \%$ and Pessimist $=90 \%$ )

2) What is the probability to failure in start up turbine if supervision is not good? (Optimist $=20 \%$ and Pessimist $=40 \%$ )

3) What is the probability to failure in start up turbine 
if training is not good? (Optimist $=40 \%$ and Pessimist $=$ $60 \%)$

4) What is the probability to failure in start up turbine if training, procedure and supervision are not good? (Optimist $=90 \%$ and Pessimist $=100 \%$ )

5) What is the probability to failure in start up turbine if procedure and supervision are not good and training is good? (Optimist $=80 \%$ and Pessimist $=90 \%$ )

6) What is the probability to failure in start up turbine if procedure and training are not good and supervision is good? $($ Optimist $=80 \%$ and Pessimist $=90 \%$ )

7) What is the probability to failure in start up turbine if procedure is not good and supervision and training is good? (Optimist $=60 \%$ and Pessimist $=70 \%$ ).

8) What is the probability to failure in start up turbine if supervision and training are not good and procedure is good? (Optimist $=20 \%$ and Pessimist $=30 \%$ )

9) What is the probability to failure in start up turbine if supervision is not good and procedure and training is good? $($ Optimist $=10 \%$ and Pessimist $=20 \%$ )

10) What is the probability to failure in start up turbine if training is not good and procedure and supervision is good? $($ Optimist $=1 \%$ and Pessimist $=0 \%$ )

11) What is the probability to failure in start up turbine if supervision procedure and training are good? (Optimist $=0 \%$ and Pessimist $=0 \%$ ).

This questionnaire comes from conditional probability equation and input probability values in Bayesian method the result.

Applying such values, in E\&P Office software and performing simulation, the Human Error Probability is 44\% as shown in Figure 4.

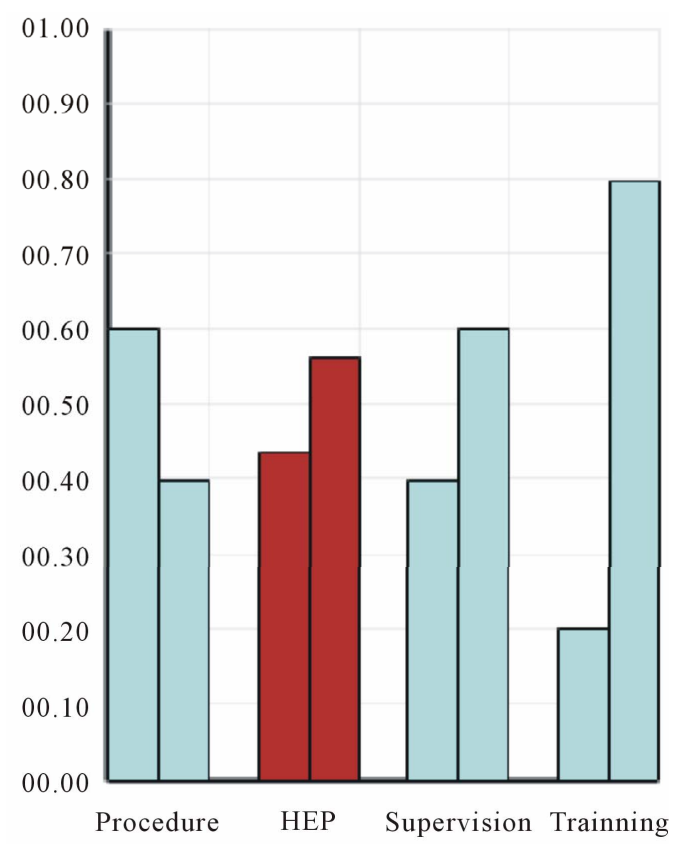

Figure 4. Bayesian network results (before improvement).
After implementing procedure improvement specialist believe that failure in start up turbine due to procedure goes down from $60 \%$ to $10 \%$. That reduces the startup failure from $46 \%$ to $13 \%$ as shown in Figure 5.

Regarding $44 \%$ of Human Error Probability the expected cost of human failure vary from U\$ 575.00 to U\$ 207.00000 in optimist and pessimist terms respectively.

After improvement, regarding 13\% of Human Error Probability the expected cost of human failure vary from U\$ 162.50 to U\$ 58.50000. The reduction in cost varies from U\$ 412.50 to U\$ 148.50000 .

The group of specialist which carried out the Network Bayesian analysis regarded about method that:

$\Rightarrow$ Bayesian Network is not easy to be implemented cause mathematics treatments and questionnaire;

$\Rightarrow$ The specialist opinion takes high influence in HEP value;

$\Rightarrow$ To have one software make easier to calculate final HEP, without software is not enable to perform such analysis.

\section{Conclusions}

Based on different Human reliability methods results, it is clear that the final HEP is similar for all methods. In this case, both methods had similar results regarding the same human performance factors as well as group of specialist opinion.

The specialist opinion has high influence in all methods results. Despite similar results, the Bayesian Network method is harder to be applied and to obtain the reliable answer from specialist due to complexity of such method. As much as the number of performance factors, harder will be to specialist answer precisely the questionnaire.

The second harder Human reliability method to be ap-

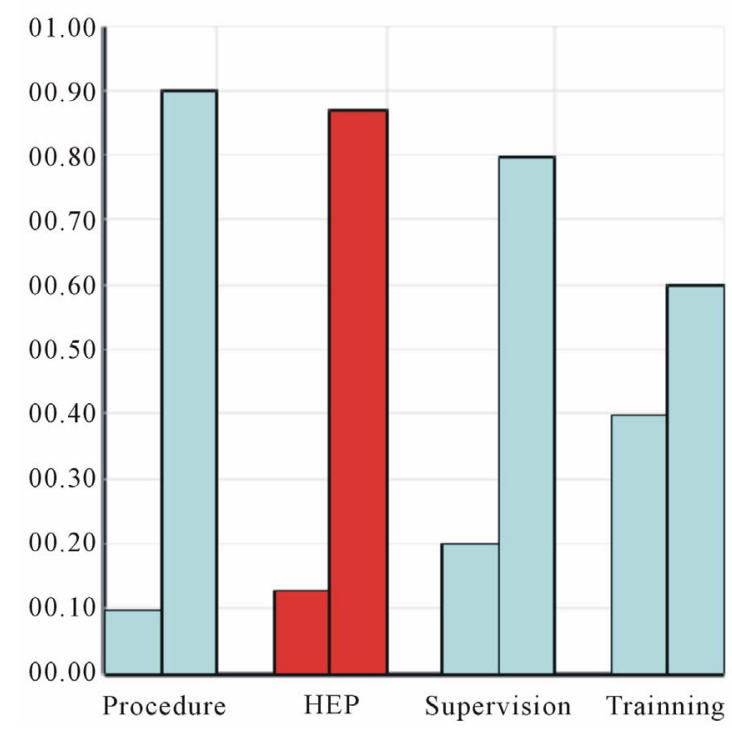

Figure 5. Bayesian network results (after improvement). 
plied is SLIM due to complexity of math involved to define the final Human error probability.

The simplest method to be applied is the SPAR-H. By the other way round, it is necessary to check if human performance factor that is being taken into account in human reliability analysis is related on Table 3 . No matter the complexity, both methods are consistent and got similar results.

The expected cost is also an important result to show the consequence of human error economically. Depends on Human reliability analysis objective, different sensitivity analysis based on human error probability can be carried out, for example risk analysis.

The future of this research is to apply such human reliability methods to analyze other maintenance tasks in order to validate the results that both methods have similar HEP result and SPAR-H is the simplest method among those methods proposed in this paper.

\section{REFERENCES}

[1] A. D. Swain and H. E. Guttmann, "Handbook of Human Reliability Analysis with Emphasis on Nuclear Power Plant Applications," Draft, NUREG/CR-1278, 1980.

[2] V. A. Silva, "O Planejamento de Emergências em Refinarias de Petróleo Brasileiras: Um Estudo dos Planos de Refinarias Brasileiras e uma Análise de Acidentes em Refinarias no Mundo e a Apresentação de uma Proposta de Relação de Canários Acidentais para Planejamento," Dissertação (Mestrado em Sistemas de Gestão) Universidade Federal Fluminense, Niterói, 2003.
[3] L. J. Bellamy, T. A. W. Geyer and J. A. Astley, "Evaluation of the Human Contribution to Pipework and In-Line Equipment Failure Frequencies," Health and Safety, London, 1989.

[4] M. Grozdanovic, "Usage of Human Reliability Quantification Methods," International Journal of Occupational Safety and Ergonomics (JOSE), Vol. 11, No. 2, 2005, pp. 153-159.

[5] A. D. Swain and H. E. Guttmann, "Handbook of Human Reliability Analysis with Emphasis on Nuclear Power Plant Applications," US Nuclear Regulatory Commission, Washington DC, 1983.

[6] "The SPAR-H Human. Reliability Analysis Method," NUREG/CR-6883, INL/EXT-05-00509, Idaho National Laboratory, US Nuclear Regulatory Commission, Washington DC, 2005.

[7] D. E. Embrey, P. Humphreys, E. A. Rosa, B. Kirwan and K. Rea, "SLIM-MAUD: An Approach to Assessing Human Error Probabilities Using Structured Expert Judgment, Volume 2: Detailed Analysis of the Technical Issues," NUREG/CR-3518, Brookhaven National Laboratory, Upton, 1984.

[8] R. da C. L. Menezes, "Uma Metodologia para Avaliação da Confiabilidade Humana em Atividades de Substituição de Cadeias de Isoladores em Linhas de Transmissão," Dissertação de Mestrado, UFPE, Recife, 2005.

[9] K. B. Korb and A. E. Nicholson, "Bayesian Artificial Intelligence," Chapman \& Hall/CRC, Boca Raton, 2003.

[10] D. E. Lopez, "Análise da Confiabilidade Humana via Redes Bayesianas: Uma Aplicação à Manutenção de Linhas de Transmissão," Produção, Vol. 17, No. 1, 2007, pp. 162-185. doi:10.1590/S0103-65132007000100012 